\title{
Insights uncovered from experiencing a rise in the incidence of gestational diabetes at a Melbourne hospital
}

\author{
Elisabeth $\mathrm{Ng}^{1}$ (D) Madeleine $\mathrm{Neff}^{2} \cdot$ Shoshana Sztal-Mazer ${ }^{3}$ \\ Received: 28 March 2018 / Accepted: 16 April 2018 / Published online: 27 April 2018 \\ (C) Springer-Verlag GmbH Germany, part of Springer Nature 2018
}

Keywords Diagnostic criteria · Gestational diabetes · Incidence

\author{
Abbreviations \\ 2HG $2 \mathrm{~h}$ plasma glucose \\ ADIPS Australasian Diabetes in Pregnancy Society \\ GDM Gestational diabetes mellitus
}

To the Editor: It is with great interest that we read the recent publication in Diabetologia entitled 'New diagnostic criteria for gestational diabetes mellitus and their impact on the number of diagnoses and pregnancy outcomes' [1], in which Koning et al address the contentious recent change in diagnostic criteria for gestational diabetes mellitus (GDM). In evaluating the impact of the WHO 2013 criteria compared with the WHO 1999 criteria, they identified that women diagnosed with GDM based on the new, lower fasting blood glucose criteria of 5.1-6.9 $\mathrm{mmol} / 1 \mathrm{had}$ an increased risk of adverse outcomes if not treated, as compared with women with normal glucose tolerance. Hence, they concluded that the lower fasting blood glucose level criteria of $\geq 5.1 \mathrm{mmol} / \mathrm{l}$ is justified and should be adopted in the Netherlands, where their study was carried out. Following on from this, Koning et al expressed concern about relaxing the $2 \mathrm{~h}$ plasma glucose $(2 \mathrm{HG})$ criteria for GDM, suggesting further studies are required to assess the outcomes of women with a $2 \mathrm{HG}$ between 7.8 and $8.4 \mathrm{mmol} / \mathrm{l}$, who would no longer receive treatment for GDM based on these new

Elisabeth $\mathrm{Ng}$

elisabethhng@gmail.com

1 Department of Medicine, Alfred Health, 55 Commercial Road, Melbourne, VIC 3004, Australia

2 Department of Nutrition \& Dietetics, Alfred Health, Melbourne, VIC, Australia

3 Department of Endocrinology \& Diabetes, Alfred Health, Melbourne, VIC, Australia criteria. The article also describes a global increase in the incidence of GDM since adopting the WHO 2013 criteria, despite the lack of international consensus regarding which GDM diagnostic criteria to use.

Here, we report our experiences with the rising incidence of GDM at The Women's at Sandringham, a multi-ethnic, metropolitan maternity hospital in Melbourne, Australia. Diagnostic criteria for GDM in Australia are guided by the Australasian Diabetes in Pregnancy Society (ADIPS). In 2012, these guidelines were updated to mirror those of the International Association of Diabetes and Pregnancy Study Group, which were then endorsed by the WHO in 2013. A change in diagnostic thresholds was recommended based on the correlation between maternal hyperglycaemia and adverse perinatal outcomes demonstrated by the Hyperglycaemia and Adverse Pregnancy Outcome study [2]. The change in criteria saw a rise in incidence rates of GDM worldwide by up to 3.5-fold [3-5]. This prompted us to audit our processes to describe the change in incidence of GDM in our hospital after adopting the new diagnostic criteria in January 2015. We also recorded the compensatory measures planned, and eventually taken, to accommodate for the rise in GDM incidence. Prior to this, our diagnosis of GDM was guided by the ADIPS 1991 criteria, based on a fasting blood glucose level of $\geq 5.5 \mathrm{mmol} / 1$ and $2 \mathrm{HG}$ of $\geq 8.0 \mathrm{mmol} / \mathrm{l}$. Of note, we transitioned from the two-step glucose challenge to the pregnancy OGTT for GDM diagnosis in April 2013.

Following our hospital's adoption of the new criteria, we experienced a $29.7 \%$ increase in the incidence of GDM from 2014 to 2015, and a $41.7 \%$ increase from 2014 to 2016 (see Table 1). This rise in incidence observed in our hospital is consistent with the $45 \%$ increase reported by Koning et al and can largely be attributed to lowering of the fasting blood glucose level criteria for diagnosis from $\geq 5.5$ to $\geq 5.1 \mathrm{mmol} / \mathrm{l}$. Consideration should also be given to the rising rates of obesity, which may contribute to the increased incidence of GDM 
Table 1 Incidence of GDM at The Royal Women's Hospital at Sandringham during the transition in diagnostic criteria for GDM

\begin{tabular}{lllll}
\hline Year (January - December) & $\begin{array}{l}\text { Absolute number of } \\
\text { new GDM diagnoses }\end{array}$ & $\begin{array}{l}\text { Number of women } \\
\text { receiving antenatal care }\end{array}$ & $\begin{array}{l}\text { Incidence } \\
\text { of GDM (\%) }\end{array}$ & $\begin{array}{l}\text { Relative increase in incidence } \\
\text { from previous year (\%) }\end{array}$ \\
\hline 2012 & 98 & 1245 & 7.87 & - \\
2013 & 117 & 1516 & 7.72 & -1.91 \\
2014 & 121 & 1480 & 8.18 & 5.96 \\
2015 & 167 & 1574 & 10.61 & 29.71 \\
2016 & 181 & 1562 & 11.59 & 9.24 \\
\hline
\end{tabular}

but to a lesser degree [5,6]. Moreover, it is important to note that the sharp rise in GDM incidence has been offset by the simultaneous loosening of the $2 \mathrm{HG}$ criteria from 8.0 to $8.5 \mathrm{mmol} / \mathrm{l}$, without which we would anticipate more dramatic changes to the incidence of GDM. We agree with Koning et al regarding the need to pursue further evidence for whether women with a $2 \mathrm{HG}$ between 7.8 and $8.4 \mathrm{mmol} / \mathrm{l}$ can be safely left untreated. However, it is necessary to consider the rise in incidence and financial cost that will likely accompany adoption of a lower $2 \mathrm{HG}$ threshold.

The rising incidence of GDM has been accompanied by a heavier fiscal burden due to the increased demand on outpatient services required to manage women with GDM. Optimal management of GDM involves a multidisciplinary approach where medical, dietetic and diabetes nurse educator services are engaged promptly. As such, the greater incidence of GDM has necessitated the implementation of significant compensatory measures in our service. Whilst we have successfully doubled the number of medical staff in our clinic, we have also had to alter our model of care by limiting medical consults to patients requiring medication reviews, with the majority of patients being monitored by a dietitian or diabetes nurse educator. These reviews are also increasingly being performed via phone calls and emails, with educational information being propagated online instead of in person to rationalise individual consults. Although business cases have been submitted requesting more nursing and dietitian support, only an additional clinic nurse coordinator has been approved to date. Greater demand has also been placed on pathology and clerical staff whose working hours have increased. Adding to the financial burden are the cost of purchasing blood glucose monitoring equipment, the price of insulin and the other pathology costs, such as increased $\mathrm{HbA}_{1 \mathrm{c}}$ testing and post-partum OGTTs. It must be considered, however, that this increase in outpatient costs may potentially be compensated by reduced inpatient costs, as indicated by one group who reported a reduction in the overall financial burden of GDM using these new criteria [3]. Nevertheless, resources are not always drawn from the same pool so careful planning must occur.

On an epidemiological level, the above findings reaffirm the role of preventative strategies in reducing the burden of disease. It has been demonstrated that improved preconception care leads to improvements in glycaemic control, which correspond to better maternal and fetal outcomes [7]. As such, the role of public health could be maximised to prevent GDM through lifestyle measures pre-pregnancy.

Whilst lowering the threshold for diagnosis of GDM may improve patient outcomes, as Koning et al suggest, the resultant financial impact and strain on services should be concurrently assessed. If unprepared to provide bolstered outpatient resources for the sudden increase in GDM incidence, existing services may be overwhelmed, and the standard of care compromised for all patients. We support the need for further studies to justify lowering the threshold for GDM diagnosis and recommend early auditing of individual services to quantify the resources required to accommodate an increase in incidence. Active, pre-emptive discussion regarding best strategies to manage an increased patient workload is imperative to prevent any compromise to the safety and quality of patient care.

Acknowledgements L. Bach (Department of Endocrinology and Diabetes, Alfred Health, Australia) for participation in the discussion regarding which outpatient costs should be considered in our estimates.

Duality of interest The authors certify that they have no affiliations with, or involvement in, any organisation or entity with any financial or nonfinancial interest in the subject matter or materials discussed in this manuscript. The authors declare that there is no duality of interest associated with this manuscript.

Contribution statement All authors were responsible for drafting the article and revising it critically for important intellectual content. All authors approved the version to be published.

\section{References}

1. Koning SH, van Zanden JJ, Hoogenberg K et al (2018) New diagnostic criteria for gestational diabetes mellitus and their impact on the number of diagnoses and pregnancy outcomes. Diabetologia 61: 800-809

2. The HAPO Study Cooperative Research Group (2008) Hyperglycemia and adverse pregnancy outcomes. N Engl J Med 358:1991-2002

3. Duran A, Sáenz S, Torrejón MJ et al (2014) Introduction of IADPSG criteria for the screening and diagnosis of gestational diabetes mellitus results in improved pregnancy outcomes at a lower cost in 
a large cohort of pregnant women: the St. Carlos Gestational Diabetes Study. Diabetes Care 37:2442-2450

4. Ekeroma AJ, Chandran GS, McCowan L, Ansell D, Eagleton C, Kenealy $\mathrm{T}$ (2015) Impact of using the international association of diabetes and pregnancy study groups criteria in South Auckland: prevalence, interventions and outcomes. Aust N Z J Obstet Gynaecol 55:34-41

5. Laafira A, White SW, Griffin CJ, Graham D (2016) Impact of the new IADPSG gestational diabetes diagnostic criteria on pregnancy outcomes in Western Australia. Aust N Z J Obstet Gynaecol 56:3641

6. Cheney K, Farber R, Barratt AL et al (2018) Population attributable fractions of perinatal outcomes for nulliparous women associated with overweight and obesity, 1990-2014. Med J Aust 208:119-125

7. Owens LA, Avalos G, Kirwan B, Carmody L, Dunne FP (2012) Changing clinical practice can improve clinical outcomes for women with pre-gestational diabetes mellitus. Ir Med J 105:9-11 